Rev. Adm. Saúde (On-line), São Paulo, v. 20, n. 81: e225, out. - dez. 2020, Epub 27 dez. 2020 http://dx.doi.org/10.23973/ras.81.225

ARTIGO ORIGINAL

\title{
Rotulagem de medicamentos industrializados: uma análise das diretrizes legais brasileiras e contribuições para a qualidade de produtos
}

Labeling of drug products: analysis of Brazilian legal provisions and contributions to quality

\section{Márcia Lombardo ${ }^{1}$}

1. Doutora em ciências farmacêuticas. Pesquisadora científica do Centro de Medicamentos, Cosméticos e Saneantes do Instituto Adolfo Lutz, São Paulo SP.

\section{RESUMO}

Objetivos: a rotulagem é um aspecto de qualidade fundamental no uso de medicamentos, seja pelo profissional de saúde, seja pelo paciente. Este trabalho propôs uma análise crítica do tema com base na legislação em vigor, bem como a triagem de documentos normativos úteis no processo de elaboração ou de avaliação da conformidade da rotulagem de medicamentos. Métodos: foi realizada uma pesquisa documental empregando-se como fonte de informações os sítios eletrônicos oficiais do Ministério da Saúde e da Agência Nacional de Vigilância Sanitária. Os documentos contendo itens pertinentes a rotulagem de medicamentos e classificados como vigentes ou vigentes com alteração foram selecionados para a realização do estudo. Resultados: os quesitos mais relevantes das disposições gerais e das disposições específicas da norma vigente para rotulagem de medicamentos foram sistematizados, verificando-se suas contribuições na qualidade e segurança de produtos. Embora a padronização da rotulagem de medicamentos seja necessária, a ocorrência de elevados graus de semelhança entre rótulos, embalagens ou mesmo nomenclaturas é discutida no âmbito da prática clínica e esta questão merece atenção especial. A busca de material 
complementar à legislação vigente resultou no levantamento de um total de 20 documentos, incluindo normas, guias, bancos de consulta e planilhas, que podem auxiliar no cumprimento dos requisitos de rotulagem de medicamentos.

Conclusão: rótulos de medicamentos são recursos técnicos que contribuem na eficácia e na segurança do tratamento. Os esforços das Agências Reguladoras têm permitido a consolidação de diretrizes legais para que informações e formatos adequados de rotulagem sejam aplicados nas embalagens de medicamentos industrializados. A elaboração ou a análise da rotulagem de medicamentos requer amplo conhecimento regulatório, o qual é dinâmico e, portanto, um grande desafio.

Palavras-chave: Rotulagem de Medicamentos. Legislação de Medicamentos. Vigilância de Produtos Comercializados. Segurança do Paciente.

\section{ABSTRACT}

Objectives: the labeling of drug products is an aspect of quality that is fundamental to the use of medicines, whether by the health professional or by the patient. This work proposed a critical analysis of the current legislation on the labeling of drug products, as well as the screening of normative documents useful for the process of preparing or assessing the conformity of labels.

Methods: a documentary research was carried out using the official websites of the Ministry of Health and the National Health Surveillance Agency (Brazil) as sources of information. The documents containing relevant items on labeling of drug products and classified as current or current with changes were selected for the study. Results: the most important requirements of the general and specific provisions from the current legislation have been systematized, and their contributions to the quality and safety of products have been verified. Although the standardization of the labeling is necessary, the occurrence of high degrees of similarity between labels, packaging or even nomenclatures is discussed in the context of clinical practice and this issue deserves special attention. The search for material complementary to the current legislation resulted in the collection of a total of 20 documents, including normative documents, guides, databases and spreadsheets, which might help in complying with the requirements for the labeling of drug products. Conclusion: the labeling of drug products are technical resources that contribute to the effectiveness and safety of treatment. The efforts of the Regulatory Agencies have allowed the consolidation of legal provisions for the dissemination of appropriate information and labeling formats in the packaging of drug products. The drafting or analysis of the labels requires extensive regulatory knowledge, which is dynamic and, therefore, a great challenge.

Keywords: Drug Labeling. Legislation, Drug. Product Surveillance, Postmarketing. Patient Safety. 


\section{INTRODUÇÃO}

O direito à informação adequada e clara sobre produtos e serviços, incluindo a especificação correta das características, composição, quantidade, qualidade, preço e riscos são aspectos essenciais do Código de Defesa do Consumidor. ${ }^{1}$

No caso dos medicamentos, a garantia dos requisitos de qualidade e de segurança é uma questão prioritária da Política Nacional de Medicamentos (PNM). A PNM é um elemento fortemente relacionado ao maior acesso da população a medicamentos eficazes e seguros e à melhoria das condições da assistência à saúde. ${ }^{2}$

Incidentes e erros na terapêutica podem ser atribuídos a diversos fatores, inclusive ao uso inadequado de medicamentos. Os erros de medicação podem estar relacionados a desvios na qualidade da formulação do medicamento como também ao uso incorreto. Neste sentido, falhas na comunicação em rótulos e embalagens podem comprometer a dispensação e a administração do medicamento. ${ }^{3}$

As informações apresentadas em rótulos visam orientar pacientes e profissionais de saúde quanto à apresentação, indicação e contraindicações relacionadas ao medicamento. $O$ rótulo é um requisito técnico que permite identificar, armazenar e rastrear adequadamente o produto, além de dispor outras informações para garantir o uso seguro. ${ }^{4}$

A fiscalização de medicamentos e insumos farmacêuticos envolve em seu escopo todas as etapas da produção do medicamento, inclusive a questão da rotulagem, revelando a importância deste quesito nas ações de Vigilância Sanitária, como item fundamental para a garantia da qualidade do produto e o registro no órgão regulador. ${ }^{5,6}$

O objetivo deste trabalho foi analisar e discutir os principais aspectos da resolução vigente sobre rotulagem de medicamentos. Os objetivos específicos foram: (i) identificar nos requisitos técnicos da norma as questões relacionadas com a qualidade e a segurança de produtos; (ii) associar a norma com outros documentos regulatórios pertinentes à área farmacêutica necessários ao processo de elaboração ou de análise da adequação da rotulagem de medicamentos.

\section{MÉTODOS}

A pesquisa documental foi realizada no sítio eletrônico oficial do Ministério da Saúde e da Agência Nacional de Vigilância Sanitária (ANVISA). Primeiramente realizou-se uma consulta da resolução vigente sobre rotulagem de medicamentos seguida de análise crítica do seu conteúdo, elencando-se 
documentos técnicos e normativos relacionados à rotulagem de medicamentos. Os documentos compreenderam normas, manuais, guias e ferramentas auxiliares como bancos de consultas e planilhas. Em uma segunda etapa, estes documentos foram levantados utilizando-se o sistema Saúde Legis do Ministério da Saúde ou a página de legislação do portal eletrônico da ANVISA. Por fim, os mesmos foram verificados quanto à abordagem do tema, a vigência, a alteração ou a revogação. Os documentos que apresentaram aspectos relevantes à rotulagem de medicamentos e classificados como vigentes ou vigentes com alteração foram então selecionados para a realização deste trabalho.

\section{RESULTADOS E DISCUSSÃO}

As normas para rotulagem de medicamentos são preconizadas na Resolução de Diretoria Colegiada RDC nำ71, de 22/12/2009. Esta resolução tem o objetivo de aprimorar a forma e o conteúdo dos rótulos dos medicamentos registrados e comercializados no Brasil, de modo a garantir o acesso à informação segura e adequada em prol do uso racional. ${ }^{4}$

Em seu histórico observa-se que o ato evoluiu pela consolidação de diversas normativas, gerando alterações nestas ou até revogações de documentos. Atualmente, verifica-se que a própria RDC nำ 71, de 22/12/2009 também já sofreu alterações, dentre elas, a revogação do artigo destinado aos polivitamínicos, poliminerais e poliaminoácidos, produtos atualmente regidos pela $\mathrm{RDC}^{\circ} \mathrm{N}^{\circ} 242$, de 26/07/2018.4,7

Uma visão geral da RDC no 71, de 22/12/2009 e principais conceitos sobre rotulagem de medicamentos serão discutidos a seguir.

\section{Aspectos relevantes das disposições gerais para a rotulagem de medicamentos}

As disposições gerais da RDC no 71, de 22/12/2009 tratam de quais informações e dispositivos de rastreabilidade devem constar nas embalagens de medicamentos e como estes itens devem ser dispostos na rotulagem. Em situações determinadas a norma especifica restrições para tipos de fontes, formatação, cores ou posição dos elementos, a fim de padronizar os rótulos, facilitar a leitura e destacar informações. ${ }^{4}$

As embalagens que ficam em contato direto com o medicamento, tais como blisters (cartelas) e frascos, são denominadas embalagens primárias. ${ }^{4}$ Estas embalagens devem apresentar informações mínimas para viabilizar o uso do produto, como mostra a Tabela 1.

Tabela 1. Informações que devem constar nas embalagens primárias de medicamentos 


Descrição do item para embalagem
primária

\begin{tabular}{ll}
\hline $\begin{array}{l}\text { Nome comercial e denominação genérica } \\
\text { do(s) ativo(s) de acordo com a } \\
\text { Denominação Comum Brasileira (DCB) }\end{array}$ & $\begin{array}{l}\text { Para medicamentos genéricos não } \\
\text { há nome comercial }\end{array}$ \\
\hline Concentração do(s) fármaco(s) & $\begin{array}{l}\text { Unidade de medida (ex. } 5 \mathrm{mg} / \mathrm{mL}, 5 \\
\mathrm{mg} / \mathrm{g}) \text { ou unidade farmacotécnica } \\
\text { (ex. } 5 \mathrm{mg} ; \text { comprimidos) }\end{array}$
\end{tabular}

$\begin{array}{ll}\text { Via de administração } & \text { Ex. uso oral, uso tópico } \\ \text { Nome da empresa titular do registro } & \begin{array}{l}\text { Pode ser apresentada na forma de } \\ \text { logomarca que contenha o nome da } \\ \text { empresa titular do registro }\end{array}\end{array}$

\begin{tabular}{ll}
$\begin{array}{l}\text { Telefone do serviço de atendimento ao } \\
\text { consumidor }\end{array}$ & SAC \\
\hline Número do lote & Referente ao lote de fabricação \\
\hline Data de fabricação & $\begin{array}{l}\text { Item facultativo; o formato Mês/Ano } \\
\text { pode ser utilizado }\end{array}$ \\
\hline Data de validade & $\begin{array}{l}\text { O formato Mês/Ano pode ser } \\
\text { utilizado }\end{array}$ \\
\hline
\end{tabular}

$\begin{array}{ll}\text { A frase "Venda sob prescrição médica" } & \begin{array}{l}\text { Para medicamentos de venda no } \\ \text { comércio que exigem prescrição de } \\ \text { receita }\end{array} \\ \text { A frase "Proibida venda ao comércio" } & \begin{array}{l}\text { Apenas no caso de destinação } \\ \text { institucional }\end{array}\end{array}$

Fonte: $\operatorname{RDC}^{\circ}{ }^{\circ} 71$, de 22/12/2009. ${ }^{4}$

É importante que o nome comercial, a Denominação Comum Brasileira (DCB) do fármaco e a concentração do fármaco sejam repetidamente descritas nas embalagens primárias destrutíveis e com mais de uma dose, como ocorre com os blisters, a fim de permitir a identificação do medicamento ao longo de todo o tratamento. Já as embalagens fracionáveis devem atender as regras de rotulagem dispostas em norma específica. ${ }^{4,8}$

As embalagens mais externas e que ficam em contato com a embalagem primária ou qualquer envoltório intermediário do produto são denominadas embalagens secundárias, como por exemplo, os cartuchos de cartolina. As embalagens secundárias apresentam um maior número de informações que as embalagens primárias. Eventualmente, as embalagens primárias também podem conter informações utilizadas nas embalagens secundárias, desde que a legibilidade das informações obrigatórias anteriormente mencionadas na Tabela 1 não seja prejudicada. ${ }^{4}$ 
Além dos itens previstos para as embalagens primárias (Tabela 1), as embalagens secundárias devem apresentar as informações descritas na Tabela 2.

Tabela 2. Informações a serem incluídas nas embalagens secundárias de medicamentos, além das informações mínimas exigidas na embalagem primária

\begin{tabular}{ll}
\hline $\begin{array}{l}\text { Descrição do item para } \\
\text { embalagem secundária }\end{array}$ & Observação* \\
\hline $\begin{array}{l}\text { Concentração da } \\
\text { equivalência sal base do } \\
\text { fármaco }\end{array}$ & Quando aplicável \\
$\begin{array}{l}\text { Composição qualitativa dos } \\
\text { excipientes, conforme a DCB }\end{array}$ & Item facultativo \\
\hline
\end{tabular}

\begin{tabular}{|ll}
$\begin{array}{l}\text { Quantidade total de } \\
\text { medicamento na embalagem }\end{array}$ & $\begin{array}{l}\text { Peso líquido, volume, unidade farmacotécnica, } \\
\text { conforme o caso }\end{array}$ \\
\hline Forma farmacêutica & $\begin{array}{l}\text { Ex. comprimidos, cápsulas, drágeas, solução oral, } \\
\text { solução injetável, pomada; a forma farmacêutica } \\
\text { pode ser disposta junto com a quantidade total (ex. } \\
30 \text { comprimidos) }\end{array}$ \\
\hline
\end{tabular}

\begin{tabular}{ll}
$\begin{array}{l}\text { Quantidade total de } \\
\text { acessórios dosadores }\end{array}$ & $\begin{array}{l}\text { Quando aplicável (ex. copo medida, seringa } \\
\text { dosadora, aplicador) }\end{array}$ \\
\hline Restrição de uso & $\begin{array}{l}\text { Conforme descrito na bula do medicamento } \\
\text { referência; ex. Uso adulto e pediátrico acima de 12 } \\
\text { anos }\end{array}$
\end{tabular}
Data de fabricação e de $\quad$ O formato Mês/Ano pode ser utilizado; no caso de validade relevo negativo ou positivo, estes devem ter cor ou manter nítido o contraste com a cor do fundo

Cuidados de conservação, definidos com base nos Faixa de temperatura de conservação e condições estudos de estabilidade do medicamento

\begin{tabular}{ll}
$\begin{array}{l}\text { Nome e endereço da } \\
\text { empresa titular do registro } \\
\text { no Brasil }\end{array}$ & $\begin{array}{l}\text { Dados das empresas que estão envolvidas na } \\
\text { comercialização, fabricação, importação e/ou } \\
\text { embalagem podem ser indicados }\end{array}$ \\
$\begin{array}{l}\text { Cadastro Nacional de } \\
\begin{array}{l}\text { Pessoa Jurídica da empresa } \\
\text { titular do registro }\end{array}\end{array}$ & CNPJ \\
$\begin{array}{ll}\text { Logomarca da empresa } \\
\text { titular do registro }\end{array}$ & $\begin{array}{l}\text { Item facultativo; logomarcas dos responsáveis pela } \\
\text { comercialização, fabricação, e/ou embalagem } \\
\text { podem ser indicados, desde que as informações }\end{array}$ \\
\hline
\end{tabular}




\begin{tabular}{|c|c|}
\hline & obrigatórias não sejam prejudicadas \\
\hline A frase "Indústria Brasileira" & Quando aplicável \\
\hline $\begin{array}{l}\text { Nome do responsável } \\
\text { técnico e seu número de } \\
\text { registro no Conselho Federal } \\
\text { de Farmácia (CRF) }\end{array}$ & $\begin{array}{l}\text { Nome completo, sigla do CRF e número de registro } \\
\text { no CRF }\end{array}$ \\
\hline $\begin{array}{l}\text { Número de registro do } \\
\text { produto no Ministério da } \\
\text { Saúde (MS) }\end{array}$ & Sigla MS seguida do número de registro \\
\hline $\begin{array}{l}\text { A frase "Todo medicamento } \\
\text { deve ser mantido fora do } \\
\text { alcance das crianças" }\end{array}$ & Frase de advertência \\
\hline $\begin{array}{l}\text { A frase "Informações ao } \\
\text { paciente, indicações, } \\
\text { contraindicações e } \\
\text { precauções: vide bula" }\end{array}$ & $\begin{array}{l}\text { Ou "Informações ao profissional de saúde, } \\
\text { indicações, contraindicações e precauções: vide } \\
\text { bula", conforme o caso }\end{array}$ \\
\hline $\begin{array}{l}\text { Frases específicas de } \\
\text { advertência, dependendo de } \\
\text { cada caso }\end{array}$ & Segundo normas específicas \\
\hline
\end{tabular}

Fonte: $\mathrm{RDC} \mathrm{n}^{\circ} \mathrm{71}$, de 22/12/20094; *Os rótulos das embalagens secundárias também devem constar as informações que são exigidas na embalagem primária (vide Tabela1).

Ressalta-se que as informações para orientar indivíduos com deficiência visual são obrigatórias nas embalagens secundárias de medicamentos dispensados ao paciente, visando à promoção da acessibilidade ao medicamento. Neste caso, o nome comercial ou na sua ausência a DCB deve ser gravado em Braille, sem afetar a legibilidade das informações já impressas no rótulo. 4,9

Em qualquer tipo de embalagem é imprescindível que os números de lote e de datas de fabricação/validade sejam impressos de forma legível e indelével. Para garantir a inviolabilidade do produto, lacres ou selos de segurança com identificação personalizada do laboratório devem ser colocados em todas as aberturas das embalagens secundárias ou daqueles medicamentos que são disponibilizados somente em embalagens primárias passíveis de abertura, tais como frascos. Os lacres ou selos de segurança devem permitir a detecção de rompimento e ser irrecuperáveis. ${ }^{4}$

O emprego de mecanismos capazes de rastrear o produto desde a fabricação até a dispensação é incentivado. Códigos de barras (GTIN - Global Trade Item Number) podem ser facultativamente incluídos em embalagens secundárias ou quando ausentes, em embalagens primárias. O mesmo também é válido para a tinta reativa, que após a raspagem deve revelar a palavra "Qualidade" e a logomarca da empresa titular do registro. , $^{, 10}$ 
Informações falsas, incorretas, causadoras de equívocos e confusões ou sugestivas de que o não uso do medicamento poderá afetar a saúde são indicações expressamente proibidas em rótulos de medicamentos. Figuras anatômicas para orientar pacientes e profissionais de saúde quanto ao uso correto do medicamento são permitidas, entretanto, imagens de pessoas fazendo o uso do medicamento, selos ou marcas que representem interesses de consumidores e profissionais de saúde e figuras que remetam ao sabor do produto são proibidos. O sabor poderá ser informado no rótulo, mas não poderá ser representado, a fim de evitar o consumo indiscriminado de medicamentos, principalmente por crianças. ${ }^{4,11}$

Se por um lado a padronização da rotulagem de medicamentos é necessária, a ocorrência de elevados graus de similaridade entre embalagens é indesejável, não só por questões comerciais, mas também por questões de segurança. Erros de dispensação e administração de medicamentos podem estar associados a semelhanças entre embalagens ou mesmo nomes de produtos. ${ }^{12}$

A norma sobre rotulagem de medicamentos deixa claro que é proibido utilizar rótulos com layout semelhante a outro produto registrado anteriormente por outra empresa, de mesmo ativo, concentração e forma farmacêutica. ${ }^{4}$

Entretanto, discute-se que ainda não existem diretrizes para prevenir similaridades ou manter um padrão que diferencie as mais variadas famílias de fármacos. Além disso, não raro os fabricantes utilizam artes gráficas muito semelhantes em diferentes produtos, favorecendo equívocos. ${ }^{12}$ Tais considerações representam novas perspectivas para a regulação e Vigilância de medicamentos.

Lopes et al. (2012) verificaram alto grau de semelhança entre embalagens e rótulos de medicamentos utilizados em um hospital universitário, especialmente nas embalagens de soluções parenterais de pequeno volume, como ampolas, frascos-ampola e bolsas sistema-fechado, que são itens críticos na segurança do paciente hospitalar. ${ }^{12}$

A norma sobre rotulagem de medicamentos dispõe de algumas regras específicas para a rotulagem de soluções parenterais, incluindo elementos coloridos de sinalização dos recipientes, tais como as ampolas. ${ }^{4}$ De acordo com Lopes et al. (2012), os rótulos autoadesivos são cada vez mais utilizados em ampolas e mais promissores em comparação às ampolas de vidro gravadas, uma vez que permitem a impressão de recursos gráficos e códigos de barras para rastreamento das unidades. ${ }^{12}$

Diversos autores discutem ainda a existência de similaridade ortográfica ou fonológica entre algumas substâncias medicamentosas, as quais podem se tornar fontes potenciais de erro na prática clínica. ${ }^{13,14}$

Além de falhas no preparo ou no cálculo da dose, os erros de medicação podem envolver medicamentos com aparência ou nomes semelhantes, embalagens contendo rótulos confusos, incompletos ou imprecisos, trocas de seringas, ampolas ou etiquetas ou mesmo a ausência de rotulagem nas embalagens. ${ }^{14}$ 
Por isso, uma rotulagem adequada pode contribuir na prevenção ou redução de erros associados a medicamentos. Medidas para uniformizar práticas seguras no ambiente hospitalar incluem a melhoria dos rótulos dos produtos, por meio de estratégias como inserção de letras maiúsculas nas nomenclaturas dos fármacos (tal-man lettering), codificações por cores, uso de símbolos ou etiquetas especiais e implantação de sistemas de códigos de barras. ${ }^{13}$

As recomendações para rotulagem e codificação de medicamentos utilizados em anestesia incluem a melhoria da legibilidade e conteúdo dos rótulos, bem como a repetição atenta durante a leitura dos mesmos. Os sistemas hospitalares devem ser projetados para reduzir a probabilidade de erros na identificação de medicamentos, citando-se como ações de interesse o aprimoramento de normas para a rotulagem de ampolas e frascos, o emprego de mecanismos eletrônicos e digitais de dupla-checagem e a adoção de protocolos de verificação dos medicamentos na sala de cirurgia. ${ }^{14}$

\section{Aspectos relevantes das disposições específicas para a rotulagem de medicamentos}

As disposições específicas da RDC no 71, de 22/12/2009 tratam de informações relacionadas a características particulares do produto. ${ }^{4}$ Neste contexto, o estudo de normas específicas é essencial para auxiliar a composição adequada dos elementos pertinentes à rotulagem do medicamento em questão.

O Quadro 1 mostra diferentes categorias de medicamentos cujas características requerem elementos específicos em seus rótulos. Os medicamentos foram divididos em três grandes grupos, visando uma compreensão didática. Um mesmo produto pode se enquadrar em mais de uma categoria, seja do mesmo grupo, seja de grupos diferentes, concomitantemente.

Quadro 1. Características que exigem elementos específicos na rotulagem de medicamentos.

\begin{tabular}{|c|c|c|}
\hline $\begin{array}{l}\text { Restrição de } \\
\text { uso/venda do } \\
\text { medicamento }\end{array}$ & $\begin{array}{l}\text { Categorias específicas de } \\
\text { medicamentos }\end{array}$ & $\begin{array}{l}\text { Características } \\
\text { farmacotécnicas do } \\
\text { produto }\end{array}$ \\
\hline Venda livre & $\begin{array}{l}\text { Medicamento oriundo de } \\
\text { Laboratório Oficial }\end{array}$ & Reconstituição e uso oral \\
\hline $\begin{array}{l}\text { Venda sob } \\
\text { prescrição médica }\end{array}$ & Medicamento dinamizado & $\begin{array}{l}\text { Prazo de validade alterado } \\
\text { após aberto }\end{array}$ \\
\hline
\end{tabular}




\begin{tabular}{|l|l|l|}
\hline $\begin{array}{l}\text { Fármacos sujeitos a } \\
\text { controle especial }\end{array}$ & Medicamento fitoterápico & $\begin{array}{l}\text { Presença de envoltórios } \\
\text { intermediários }\end{array}$ \\
Genérico & $\begin{array}{l}\text { Medicamento para terapia de } \\
\text { reidratação oral }\end{array}$ & $\begin{array}{l}\text { Duas ou mais apresentações } \\
\text { para uso concomitante ou } \\
\text { sequencial }\end{array}$ \\
$\begin{array}{l}\text { Destinação } \\
\text { hospitalar }\end{array}$ & $\begin{array}{l}\text { Solução parenteral de } \\
\text { pequeno ou grande volume } \\
\text { Venda proibida ao } \\
\text { comércio }\end{array}$ & $\begin{array}{l}\text { Concentrado polieletrolítico } \\
\text { para hemodiálise } \\
\text { na embalagem }\end{array}$ \\
\hline $\begin{array}{l}\text { Polivitamínicos, poliminerais } \\
\text { e poliaminoácidos }\end{array}$ & \\
\hline
\end{tabular}

Fonte: $\mathrm{RDC}^{\mathrm{0}} \mathbf{7 1}$, de 22/12/2009. ${ }^{4}$

Elementos referentes à restrição de uso/venda são inerentes a qualquer produto, portanto, estes elementos serão discutidos a seguir.

As embalagens secundárias dos medicamentos de venda livre devem conter informações claras que orientem o paciente no momento da aquisição do produto. Desse modo, as principais indicações, contraindicações e advertências comumente descritas nas bulas devem ser disponibilizadas de forma sucinta na rotulagem. Visto que estes medicamentos não exigem a prescrição do médico, a frase "Siga corretamente o modo de usar, não desaparecendo os sintomas procure orientação médica" é pertinente. Quando o medicamento é disponibilizado apenas em embalagem primária, esta deve constar qual é a faixa etária de restrição de uso (adulto ou pediátrico), o número do registro no Ministério da Saúde (MS) e a frase "Exija a bula".4,15,16

As embalagens secundárias dos medicamentos que exigem prescrição médica devem possuir faixa vermelha em toda a extensão contendo os dizeres "Venda sob prescrição médica". Frases de advertência para determinadas classes farmacológicas, ativos ou excipientes devem ser apresentadas. Quando se trata de um medicamento à base de substâncias sujeitas a controle especial, ou seja, entorpecentes e psicotrópicos, a faixa poderá ser vermelha ou preta e devem incluir frases de advertência definidas para a substância ou lista a qual pertence, de acordo com o preconizado em normas específicas. Por exemplo, certos medicamentos sujeitos a controle especial podem apresentar as frases "Venda sob prescrição médica/O abuso deste medicamento pode causar dependência" no interior de uma faixa preta. As frases específicas para medicamentos controlados também devem ser apresentadas nos rótulos das embalagens primárias. ${ }^{4,15-17}$

As embalagens primárias e secundárias de medicamentos genéricos devem incluir a frase "Medicamento genérico Lei № 9.787, de 1999". As embalagens secundárias devem apresentar também faixa amarela acima da faixa vermelha ou abaixo da faixa preta, contendo um logotipo da letra " $G$ " e os dizeres 
"Medicamento Genérico", padronizados conforme previsto na legislação. Para medicamentos genéricos exclusivamente comercializados em embalagem primária deve-se incluir a faixa amarela e o logotipo na rotulagem, como frequentemente ocorre com aqueles medicamentos de venda livre acondicionados somente em blisters. ${ }^{4,18,19}$

As embalagens secundárias dos medicamentos com destinação hospitalar devem apresentar a frase "Embalagem hospitalar", a qual é dispensada para medicamentos de uso restrito a hospitais, já que estes só podem ser administrados em ambiente hospitalar. Estes medicamentos devem então apresentar a frase "Uso restrito a hospitais" em suas embalagens secundárias. ${ }^{4}$

Os medicamentos com destinação institucional são aqueles reservados aos postos de dispensação do Sistema Único de Saúde (SUS) e, portanto, não podem ser vendidos no comércio. Por isso, todas as embalagens primárias e secundárias dos medicamentos incluídos em programas governamentais devem apresentar a frase "Proibida venda ao comércio". E, se estes medicamentos exigirem prescrição médica, a frase "Venda sob prescrição médica" poderá ser substituída por "Uso sob prescrição médica". No caso de medicamentos que são exclusivamente destinados a programas de saúde pública do Ministério da Saúde, toda a identificação visual da rotulagem segue um padrão próprio, conforme manual instituído por norma específica. 4,20

Quanto aos demais grupos do Quadro 1, a RDC № 71, de 22/12/20094 descreve as particularidades necessárias em cada situação, entretanto, a disponibilidade de normas específicas deve sempre ser consultada. Em geral, as informações requeridas para estes casos visam identificar o produto e/ou orientar o uso de forma segura. Algumas normas e documentos citados na próxima seção poderão ser úteis na rotulagem de diferentes categorias de medicamentos.

\section{Outros documentos que tratam de aspectos relacionados à rotulagem de medicamentos}

Cabe mencionar neste trabalho que as regras para rotulagem de medicamentos fundamentam-se em diversas normas pertinentes à área farmacêutica. Tal abordagem é sugerida pela própria RDC no 71, de 22/12/2009. ${ }^{4}$ Portanto, a busca de outros documentos oficiais relativos ao cumprimento dos requisitos de rotulagem é inerente, como ilustra a Tabela 3.

$\mathrm{Na}$ Tabela 3 estão compilados documentos complementares aos itens da norma vigente sobre rotulagem de medicamentos, alguns deles já citados ao longo do trabalho. Foram levantados um total de 20 documentos, incluindo 14 normas, 2 guias, 2 bancos de consulta e 2 planilhas on line periodicamente atualizadas. É importante considerar que muitas destas normas já sofreram alterações e, além disso, podem conduzir a diversos atos correlacionados, configurando riqueza de históricos e de informações sobre o tema. 
Tabela 3. Documentos que podem embasar ou complementar as diretrizes sobre rotulagem de medicamentos

\begin{tabular}{|c|c|c|}
\hline Assunto & Documento & Referência \\
\hline $\begin{array}{l}\text { Lista atualizada das Denominações } \\
\text { Comuns Brasileiras (DCB) para } \\
\text { nomes de fármacos e insumos } \\
\text { farmacêuticos }\end{array}$ & $\begin{array}{l}\text { Planilha - Lista } \\
\text { consolidada das DCB }\end{array}$ & 21 \\
\hline $\begin{array}{l}\text { Termos técnicos padronizados da } \\
\text { área farmacêutica }\end{array}$ & $\begin{array}{l}\text { Guia - Vocabulário } \\
\text { controlado de Formas } \\
\text { Farmacêuticas, Vias de } \\
\text { Administração e } \\
\text { Embalagens de } \\
\text { Medicamentos }\end{array}$ & 22 \\
\hline $\begin{array}{l}\text { Lista atualizada de medicamentos } \\
\text { referência no país }\end{array}$ & $\begin{array}{l}\text { Planilha - Listas de } \\
\text { medicamentos de } \\
\text { referência }\end{array}$ & 23 \\
\hline $\begin{array}{l}\text { Busca de bulas de medicamentos } \\
\text { registrados na Agência Nacional de } \\
\text { Vigilância Sanitária }\end{array}$ & $\begin{array}{l}\text { Banco de consulta - } \\
\text { Bulário eletrônico }\end{array}$ & 24 \\
\hline $\begin{array}{l}\text { Regras para elaboração, } \\
\text { harmonização, atualização, } \\
\text { publicação e disponibilização de } \\
\text { bulas de medicamentos para } \\
\text { pacientes e para profissionais de } \\
\text { saúde }\end{array}$ & $\begin{array}{l}\text { Norma - RDC no } 47 \text {, de } \\
\text { 08/09/2009 }\end{array}$ & 25 \\
\hline $\begin{array}{l}\text { Verificação do número/validade do } \\
\text { registro no Ministério da Saúde e } \\
\text { outras informações relacionadas ao } \\
\text { medicamento e à empresa fabricante }\end{array}$ & $\begin{array}{l}\text { Banco de consulta - } \\
\text { Consulta a produtos } \\
\text { regularizados }\end{array}$ & 26 \\
\hline $\begin{array}{l}\text { Fracionamento de medicamentos a } \\
\text { partir de embalagens especialmente } \\
\text { desenvolvidas para essa finalidade }\end{array}$ & $\begin{array}{l}\text { Norma - RDC no 80, de } \\
11 / 05 / 2006\end{array}$ & 8 \\
\hline $\begin{array}{l}\text { Mecanismos e procedimentos para } \\
\text { rastreamento de medicamentos }\end{array}$ & $\begin{array}{l}\text { Norma - RDC no } 157 \text {, de } \\
11 / 05 / 2017\end{array}$ & 10 \\
\hline $\begin{array}{l}\text { Propaganda, publicidade, informação } \\
\text { e outras práticas de divulgação ou } \\
\text { promoção comercial de } \\
\text { medicamentos }\end{array}$ & $\begin{array}{l}\text { Norma - RDC no 96, de } \\
17 / 12 / 2008\end{array}$ & 11 \\
\hline Medicamentos isentos de prescrição & $\begin{array}{l}\text { Norma - IN no 11, de } \\
29 / 09 / 2016\end{array}$ & 27 \\
\hline $\begin{array}{l}\text { Advertência para produto de uso } \\
\text { tópico contendo cânfora }\end{array}$ & $\begin{array}{l}\text { Norma - RDC n } 30 \text {, de } \\
05 / 02 / 2002\end{array}$ & 15 \\
\hline
\end{tabular}




\begin{tabular}{lll}
\hline $\begin{array}{l}\text { Frases específicas de advertência } \\
\text { para determinadas classes } \\
\text { farmacológicas, ativos ou } \\
\text { excipientes, que devem ser } \\
\text { disponibilizadas em bulas e } \\
\text { embalagens }\end{array}$ & $\begin{array}{l}\text { Norma - RDC no 137, de } \\
29 / 05 / 2003\end{array}$ \\
$\begin{array}{l}\text { Substâncias e medicamentos } \\
\text { sujeitos a controle especial, com } \\
\text { atualizações periódicas das listas de } \\
\text { substâncias entorpecentes, } \\
\text { psicotrópicas, precursoras e outras } \\
\text { sob controle especial }\end{array}$ & $\begin{array}{l}\text { Norma - PRT no 344, de } \\
12 / 05 / 1998\end{array}$ & \\
$\begin{array}{l}\text { Padrão visual das embalagens de } \\
\text { medicamentos distribuídos pelo } \\
\text { Ministério da Saúde }\end{array}$ & $\begin{array}{l}\text { Guia - Manual de } \\
\text { embalagens de } \\
\text { medicamentos }\end{array}$ & \\
\hline
\end{tabular}

\begin{tabular}{|c|c|}
\hline $\begin{array}{l}\text { Padronização do logotipo que } \\
\text { identifica as embalagens de } \\
\text { medicamentos genéricos }\end{array}$ & $\begin{array}{l}\text { Norma - RDC no } 47 \text {, de } \\
\text { 28/03/2001 }\end{array}$ \\
\hline
\end{tabular}

Registro, renovação de registro, Norma - RDC № 238, de 28 mudanças pós-registro e notificação 25/07/2018 de medicamentos dinamizados industrializados

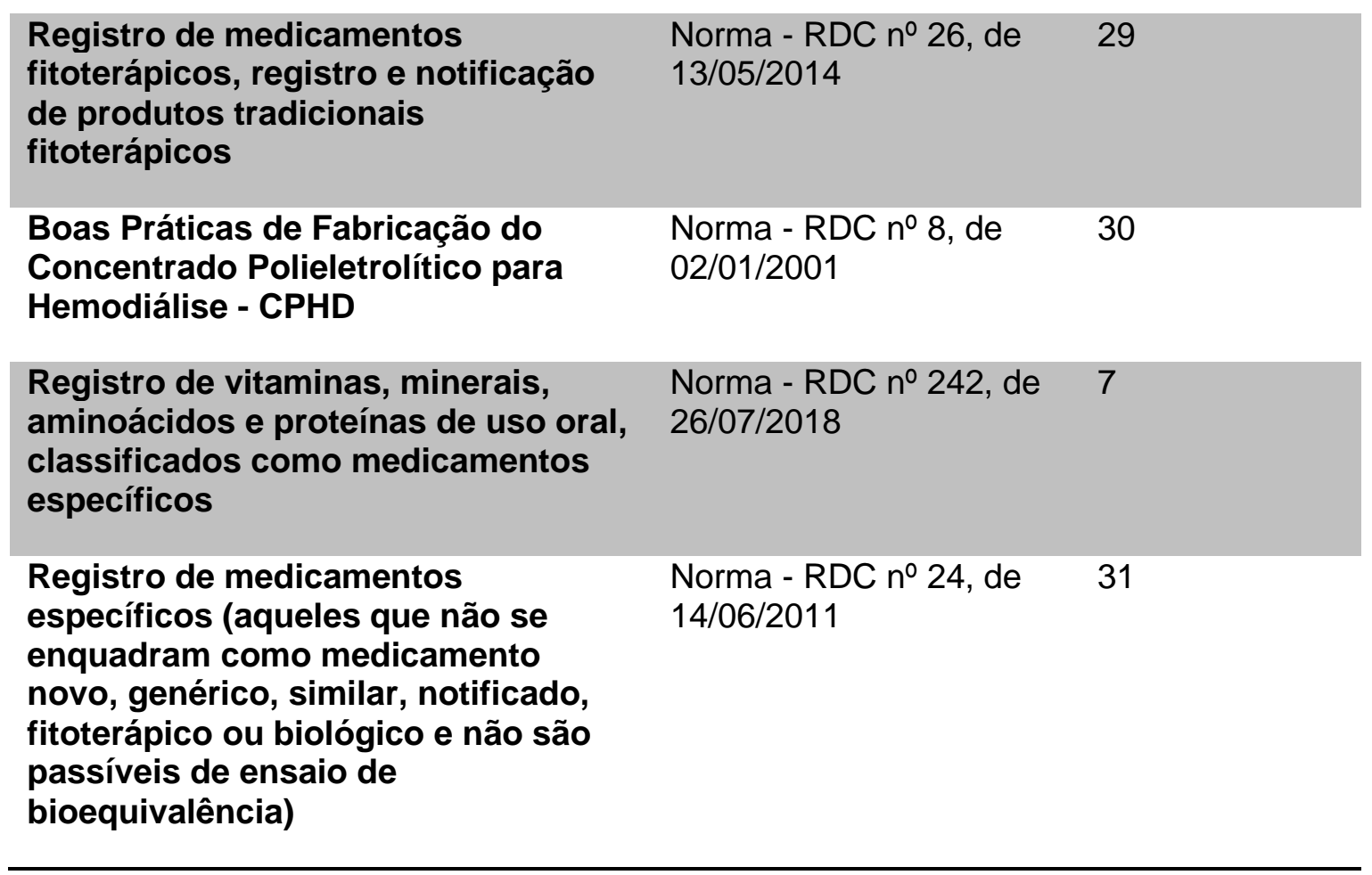

Os documentos apresentados na Tabela 3 são relevantes para compreender e padronizar conceitos e termos técnicos ou mesmo auxiliar nas informações específicas a serem disponibilizadas nos rótulos de medicamentos. Os bancos de consulta possibilitam ainda avaliar a fidedignidade de informações sobre o 
produto e a empresa fabricante. Destaca-se que os documentos levantados não esgotam o tema e estão sujeitos a alterações e atualizações, exigindo o acompanhamento contínuo das normas que regulam o setor de medicamentos.

\section{CONCLUSÃO}

Os esforços das Agências Reguladoras têm permitido a consolidação de diretrizes legais para que informações e formatos adequados de rotulagem sejam aplicados nas embalagens de medicamentos industrializados, visando à padronização de elementos que são fundamentais à segurança e à eficácia do produto. A resolução sobre rotulagem de medicamentos é rica em detalhes, 0 que permite aprofundar conhecimentos na regulamentação destes produtos. Além disso, existe uma inter-relação da norma vigente com diversos outros documentos e guias oficiais do setor farmacêutico, os quais são úteis para auxiliar o cumprimento dos requisitos exigidos na rotulagem e no registro de medicamentos de qualidade.

\section{REFERÊNCIAS}

1. Brasil. Casa Civil. Lei no 8.078, de 11 de setembro de 1990. Dispõe sobre a proteção do consumidor e dá outras providências. Diário Oficial da União, Seção I - suplemento, pág. 1, 12 de setembro de 1990.

2. Brasil. Secretaria de Políticas de Saúde. Portaria n 3.916/GM, de 30 de outubro de 1998. Política Nacional de Medicamentos. Diário Oficial da União no 15-E, Seção I, pág. 18, 10 de novembro de 1998.

3. Brasil. Ministério da Saúde. Portaria no 529/GM/MS, de 1ำ de abril de 2013. Institui o Programa Nacional de Segurança do Paciente (PNSP). Diário Oficial da União no 62, Seção I, pág. 43, 2 de abril de 2013.

4. Brasil. Agência Nacional de Vigilância Sanitária. Resolução de Diretoria Colegiada - RDC no 71, de 22 de dezembro de 2009. Estabelece regras para a rotulagem de medicamentos. Diário Oficial da União oㅡ 245, Seção I, pág. 75, 23 de dezembro de 2009.

5. Brasil. Congresso Nacional. Lei $n^{\circ} 6.360$, de 23 de setembro de 1976.

Dispõe sobre a Vigilância Sanitária a que ficam sujeitos os Medicamentos, as Drogas, os Insumos Farmacêuticos e Correlatos, Cosméticos, Saneantes e Outros Produtos, e dá outras Providências. Diário Oficial da União, Seção I, pág. 12647, 24 de setembro de 1976.

6. Lombardo M, Eserian JK. A análise da qualidade de medicamentos e o papel do laboratório oficial no contexto da saúde pública. Rev Adm Saúde. 2017;67(Abr-Jun). http://doi.org/10.23973/ras.67.28 
7. Brasil. Agência Nacional de Vigilância Sanitária. Resolução de Diretoria Colegiada - RDC no 242, de 26 de julho de 2018. Altera a [...] e a Resolução - RDC no 71, de 22 de dezembro de 2009 e regulamenta o registro de vitaminas, minerais, aminoácidos e proteínas de uso oral, classificados como medicamentos específicos. Diário Oficial da União no 144, Seção I, pág. 97, 27 de julho de 2018.

8. Brasil. Agência Nacional de Vigilância Sanitária. Resolução de Diretoria Colegiada - RDC ํㅡ 80, de 11 de maio de 2006. As farmácias e drogarias poderão fracionar medicamentos a partir de embalagens especialmente desenvolvidas para essa finalidade [...]. Diário Oficial da União ํo 90, Seção I, pág. 58-62, 12 de maio de 2006.

9. Brasil. Casa Civil. Lei no 10.098, de 19 de dezembro de 2000. Estabelece normas gerais e critérios básicos para a promoção da acessibilidade das pessoas portadoras de deficiência ou com mobilidade reduzida, e dá outras providências. Diário Oficial da União, Seção I, pág. 2, 20 de dezembro de 2000.

10. Brasil. Agência Nacional de Vigilância Sanitária. Resolução de Diretoria Colegiada - RDC no 157, de 11 de maio de 2017. Dispõe sobre a implantação do Sistema Nacional de Controle de Medicamentos e os mecanismos e procedimentos para rastreamento de medicamentos e dá outras providências. Diário Oficial da União no 91, Seção I, pág. 40, 15 de maio de 2017.

11. Brasil. Agência Nacional de Vigilância Sanitária. Resolução de Diretoria Colegiada - RDC oㅜ 96, de 17 de dezembro de 2008. Dispõe sobre a propaganda, publicidade, informação e outras práticas cujo objetivo seja a divulgação ou promoção comercial de medicamentos. Diário Oficial da União oㅡ 246, Seção I, pág. 102, 18 de dezembro de 2008.

12. Lopes DMA, et al. Análise da rotulagem de medicamentos semelhantes: potenciais erros de medicação. Rev Assoc Med Bras. 2012; 58(1):95-103. http://doi.org/10.1590/S0104-42302012000100021.

13. Godinho LF, Carreira C, Martins C. Medicamentos Look-Alike, Sound-Alike: Um Velho Conceito Sempre em Atualização. Rev Soc Port Anestesiol. 2018;27(3):20-24. http://doi.org/10.25751/rspa.15145.

14. Dhawan I, Tewari A, Sehgal S, Sinha AC. Erros de medicação em anestesia: inaceitável ou inevitável? Rev Bras Anestesiol. 2017; 67(2):184192. http://doi.org/10.1016/..bjan.2016.12.006.

15. Brasil. Agência Nacional de Vigilância Sanitária. Resolução de Diretoria Colegiada - RDC no 30, de 5 de fevereiro de 2002. Determinar que todos os produtos de uso tópico contendo cânfora em suas formulações apresentem em suas rotulagens, bulas, impressos em etiquetas e prospectos advertências nos termos desta RDC. Diário Oficial da União ํㅡㄹ, Seção I, pág. 60, 7 de fevereiro de 2002. 
16. Brasil. Agência Nacional de Vigilância Sanitária. Resolução de Diretoria Colegiada - RDC no 137, de 29 de maio de 2003. O registro/renovação de registro de medicamentos pertencentes às classes/princípios ativos relacionadas em Anexo, só serão autorizados se as bulas contiverem a advertência pertinente, conforme relação anexa. Diário Oficial da União no 104, Seção I, pág. 31, 2 de junho de 2003.

17. Brasil. Agência Nacional de Vigilância Sanitária. Portaria/SVS nํ 344, de 12 de maio de 1998. Aprova o Regulamento Técnico sobre substâncias e medicamentos sujeitos a controle especial. Diário Oficial da União no 91, Seção I, pág. 3, 15 de maio de 1998.

18. Brasil. Casa Civil. Lei no 9.787, de 10 de fevereiro de 1999. Altera a Lei no 6.360, de 23 de setembro de 1976, que dispõe sobre a vigilância sanitária, estabelece o medicamento genérico, dispõe sobre a utilização de nomes genéricos em produtos farmacêuticos e dá outras providências. Diário Oficial da União, Seção I, pág. 1, 11 de fevereiro de 1999.

19. Brasil. Agência Nacional de Vigilância Sanitária. Resolução de Diretoria Colegiada - RDC n 47, de 28 de março de 2001. Os medicamentos genéricos [...] devem ter, para facilitar a sua distinção, em suas embalagens externas, o logotipo que identifica o medicamento genérico [...]. Diário Oficial da União no 63, Seção I, pág. 57, 30 de março de 2001.

20. Agência Nacional de Vigilância Sanitária. Manual de embalagens de medicamentos. 2ª edição [Internet]. Brasília, DF: Ministério da Saúde/ Agência Nacional de Vigilância Sanitária; 2014. [citado 23 abr. 2020]. Disponível em:

http://portal.anvisa.gov.br/documents/33836/351410/Manual+de+Embalage $\underline{\text { ns+de+Medicamentos/6be34884-01eb-4aea-b2d8-1935b2313437 }}$

21. Agência Nacional de Vigilância Sanitária. Lista das Denominações Comuns Brasileiras [Internet]. Brasília, DF: Agência Nacional de Vigilância Sanitária [citado 23 abr. 2020]. Disponível em:

http://portal.anvisa.gov.br/denominacao-comum-brasileira

22. Agência Nacional de Vigilância Sanitária. Vocabulário Controlado de Formas Farmacêuticas, Vias de Administração e Embalagens de Medicamentos [Internet]. Brasília, DF: Agência Nacional de Vigilância Sanitária; 2011 [citado 23 abr. 2020]. Disponível em: http://portal.anvisa.gov.br/documents/33836/2501339/Vocabul\%C3\%A1 rio+ Controlado/fd8fdf08-45dc-402a-8dcf-fbb3fd21ca75

23. Agência Nacional de Vigilância Sanitária. Lista de Medicamentos de Referência [Internet]. Brasília, DF: Agência Nacional de Vigilância Sanitária [citado 23 abr. 2020]. Disponível em: http://portal.anvisa.gov.br/registros-e autorizacoes/medicamentos/produtos/medicamentos-de-referencia/lista

24. Ministério da Saúde. Bulário eletrônico [Internet]. Brasília, DF: Agência Nacional de Vigilância Sanitária [citado 23 abr. 2020]. Disponível em: http://www.anvisa.gov.br/datavisa/fila bula/index.asp 
25. Brasil. Agência Nacional de Vigilância Sanitária. Resolução de Diretoria Colegiada - RDC no 47, de 8 de setembro de 2009. Estabelece regras para elaboração, harmonização, atualização, publicação e disponibilização de bulas de medicamentos para pacientes e para profissionais de saúde. Diário Oficial da União oํ 172, Seção I, pág. 31, 9 de setembro de 2009.

26. Agência Nacional de Vigilância Sanitária. Consulta a produtos regularizados [Internet]. Brasília, DF: Agência Nacional de Vigilância Sanitária [citado 23 abr. 2020]. Disponível em: http://portal.anvisa.gov.br/consulta-produtosregistrados

27. Brasil. Agência Nacional de Vigilância Sanitária. Instrução Normativa - IN no 11, de 29 de setembro de 2016. Dispõe sobre a lista de medicamentos isentos de prescrição. Diário Oficial da União № 189, Seção I, pág. 99, 30 de setembro de 2016.

28. Brasil. Agência Nacional de Vigilância Sanitária. Resolução de Diretoria Colegiada - RDC n 238, de 25 de julho de 2018. Dispõe sobre o registro, a renovação de registro, as mudanças pós-registro e a notificação de medicamentos dinamizados industrializados. Diário Oficial da União no 144 , Seção I, pág. 82, 27 de julho de 2018.

29. Brasil. Agência Nacional de Vigilância Sanitária. Resolução de Diretoria Colegiada - RDC no 26, de 13 de maio de 2014. Dispõe sobre o registro de medicamentos fitoterápicos e o registro e a notificação de produtos tradicionais fitoterápicos. Diário Oficial da União no 90, Seção I, pág. 52, 14 de maio de 2014.

30. Brasil. Agência Nacional de Vigilância Sanitária. Resolução de Diretoria Colegiada - RDC o 8, de 2 de janeiro de 2001. Aprovar o Regulamento Técnico que institui as Boas Práticas de Fabricação do Concentrado Polieletrolítico para Hemodiálise - CPHD. Diário Oficial da União № 7, Seção I, pág. 40, 10 de janeiro de 2001.

31. Brasil. Agência Nacional de Vigilância Sanitária. Resolução de Diretoria Colegiada - RDC no 24, de 14 de junho de 2011. Dispõe sobre o registro de medicamentos específicos. Diário Oficial da União № 116, Seção I, pág. 79, 17 de junho de 2011. 
Recebido: 09 de fevereiro de 2019. Aceito: 30 de setembro de 2020

Correspondência: Márcia Lombardo. E-mail: marcia.lombardo@ial.sp.gov.br

Conflito de Interesses: os autores declararam não haver conflito de interesses.

(C) This is an Open Access article distributed under the terms of the Creative Commons Attribution License, which permits unrestricted use, distribution, and reproduction in any medium, provided the original work is properly cited 